\title{
Application of AIDS Model
}

\author{
K.L. Muruganantha Prasad, V. Geetha, S. Mookan
}

\section{INTRODUCTION}

The green revolution was the introduction of high yielding varieties (HYV). In 1960, the total area under the HYV was only 1.9 million hectares; it increased to almost 15.4 million hectares by $1970,43.1$ million hectares by 1980, and had grown to 63.0 million hectares by 1990 (Worden and Heitzman, 1999). With the increase in area under HYV, the amount of food that was being produced multiplied greatly, with the greatest increases coming from wheat and rice production. By 1980, almost $75 \%$ of the total cropped area under wheat was sown with HYV, and almost $45 \%$ of total rice area was under HYV (Worden and Heitzman, 1999).

In Tamilnadu, the Public Distribution System (PDS) of food and non-food and the Free Noon Meal Scheme(FNMS) are the two major programmes covering the entire population of 55 millions of the State and the latter covering about 20 per cent of the population, comprising children and old under its fold. The possible impact of these programmes include (i) increase in the real income of the household,(ii) higher levels of consumption of food, (iii) reduction in malnutrition, particularly among children and (iv) overall reduction in poverty level.

Low food consumption is an indicator of the prevalence of malnutrition. Choudhry and Rao(1973), based on their study on nutritional status of pre-school children, have reported that only 16.7 per cent of the children had adequate nutrition, about 27.0 per cent of them were subject to severe, 51.6 per cent to moderate and 4.7 per cent to mild malnutrition. Obviously, the consumption and nutrition programmes along with other developmental programmes, have not had the desired impact in the past two decades. Besides the consumption of low calories, "perhaps equally important" is the poverty of literacy, health, housing and industrial consumer goods. It is here that major improvements need to emerge besides efforts for freedom from hunger.

The primary aim of all developmental efforts is to improve the quality of life of rural sector through income generation. The income is one of the most important determinants of food consumption. The knowledge of food consumption pattern at household levels and its relation to income is a logical basis for the planning of self sufficiency in agricultural production. In this respect, the effect of changes in income and demand for different foods are important in setting economic and nutritional policies. The reliable estimates of demand elasticities are essential for

Revised Manuscript Received on July 10, 2019.

K.L. Muruganantha Prasad, Department of Mathematics, H.H. The Rajahs College, Pudhukottai, Tamilnadu, India.

V. Geetha, Research Scholar, H.H. The Rajahs College, Pudhukottai, Tamilnadu, India.

S. Mookan, Department of Mathematics, PET Engineering College, Valliyoor, Tamilnadu, India. evaluation of alterative methods, levels of price support, trade, taxation and other related policies. The estimates of expenditure elasticities and consumption responses to other shifter variables and expenditure behaviour of the households would help to develop projections for future demand for various consumption items.

\section{THE CONCEPT OF DEMAND FUNCTION}

Measuring consumption is quite a difficult task. Consumption includes several components: all the individual expenditure on goods and services, a value for consumption that does not go through the market (home production, transfer in kind, etc.) and a value for durable goods possessed. For the latter some sort of consumption flow needs to be imputed. There is an important distinction to make between consumption and expenditure the former includes the value of service flows from durable items and assets (such as home, vehicles, washing machine, computers, etc.) whereas the latter includes current expenses on the purchase of these items. Theoretically, consumption is preferable to expenditure as it better reflects material resources, although in practice estimating the value of service flows involves crucial assumptions(such as definition of durable good, depreciation rate of different items, etc.). The methods adopted to construct consumption measures significantly vary among countries and over time. Most of the choices involved with the measurement of consumption are usually driven by data availability or by comparability over time within a country. There exist, however, good practice techniques and guidelines which one could look at when trying to construct an accurate measure of consumption. Total household consumption expenditure should comprise: food consumption, non food consumption, education expenditure and housing expenditure. In revising the method adopted by the Bolivian National Institute of Statistics (INE), it emerged, however, that computation of the total consumption expenditure was not clear and consistent. However, from 2005 onwards INE includes in the consumption aggregate only the current expenditure thus excluding the value of service flows of durables. Moreover, in computing current expenditure, durable goods and expenditures made in house repair and construction that are above a certain threshold are excluded because they are regarded as investment rather than consumption. As a result, a lack of consistency in the definition and construction of consumption aggregates provided by the INE is apparent and that simply prevents one from comparing those figures over time. Aware of that, the only feasible option for conducting sound research using consumption data is devoting intense effort to create original, consistent, accurate consumption estimates.

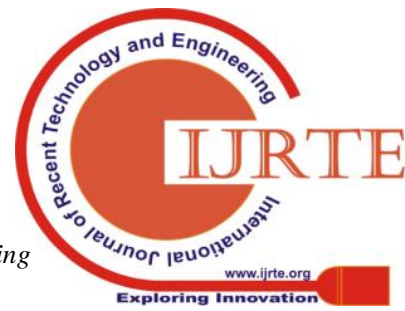




\section{Application of Aids Model}

This task, although very time consuming, represents a notable and original contribution of the present study to the literature. To estimate consumption figures the following components have been aggregated: Food consumption inside the household(food purchases, self-produced food, food from other sources-such as gifts, transfers in kind) Food consumed outside the household (breakfast, drinks, lunch/dinner, snacks,...)

Non-food consumption (aggregate of about 40 categories related to current housing costs, domestic fuel and power, tobacco products, clothing and footwear, medical care and health expenses, transport, recreation, personal care, miscellaneous goods and services.

Education expenditure (tuition fees, transport, books and copies, uniform, etc.)

Housing expenditure (actual rent or rental equivalence value, expenses- gas, water, electricity, telephone-house repair-decoration)

The computation has been done at the (per capita) household level. When the expenditure was reported at the individual level, the household aggregate has been computed and the per capita mean has then been obtained dividing the household figure by the household size. As respondents are allowed for some modules to answer in Rupees, all the values in Rupees have been converted into real inside the house such as beds, TV, microwave oven, etc. Information on the method used to impute such values.

In the case of consumption, the willingness to buy a commodity, that is the demand for that, depends on the factors such as

i. The income of the consumer

ii. The price of that commodity

iii. Prices of other goods and services on which the consumer spends his income.

iv. Tastes and preferences of the consumer, size of the family, social customs, expectations and advertisements. etc.

In the case of a farm or firm, the input demand for commodity depends on the factors like:

i. The total outlay or expenditure of the firm

ii. The price of that commodity

iii. Prices of other substitutes and complementary inputs

iv. The nature of technology, etc.

Since the study is on consumer demand, we shall restrict to it only.

A consumer demand function for a commodity specifies the relationship between quantity of the commodity that the consumer is willing to buy and the demand factors. In mathematical form, the demand function for a commodity is express as.

$$
Q_{X}=D_{X}\left[P_{X^{\prime}} P_{S^{\prime}} P_{c^{\prime}}, Y, T\right]
$$

where $Q_{x}$ is the quantity of the commodity $X$ demanded, $\mathrm{P}_{\mathrm{x}}$ is the price of the commodity, $\mathrm{P}_{\mathrm{s}}$ denotes the price of other commodity which can be substituted for $\mathrm{X}, \mathrm{P}_{\mathrm{c}}$ is the price of the commodity which is the complement of commodity $\mathrm{X}, \mathrm{Y}$ is the income of the consumer and $\mathrm{T}$ represents other demand factors such as tastes, preferences, social customs, etc, $\mathrm{D}_{\mathrm{x}}$ indicates the functional form of the relationship. There may be more than one substitute and/or complementary goods for commodity $\mathrm{X}$, In this situation the specification of the demand function for commodity $\mathrm{X}$ can be expanded by including their prices. The demand function may be linear or non-linear. It is a common observation that for most of the commodities, the willingness to buy decreases as price of the commodity increases.

\section{ALMOST IDEAL DEMAND SYSTEM (AIDS)}

To derive the equation for AIDS, the structure of the cost function is essential. Consider a production process with two inputs say $\mathrm{X}_{1}$ and $\mathrm{X}_{2}$. Let $\mathrm{C}^{0}$ be the amount of money, which a producer has for the expenditure on the two inputs. Let the input price be $P_{1}$ and $P_{2}$ for $X_{1}$ and $X_{2}$ respectively. If $x_{1}$ and $\mathrm{X}_{2}$ are the quantities of the two inputs $X_{1}$ and $X_{2}$ then the cost line is given by

$$
\mathrm{C}^{0}=\mathrm{P}_{1} \mathrm{x}_{1}+\mathrm{P}_{2} \mathrm{x}_{2}
$$

This gives the locus of all combination of the two inputs which the producer can buy using his fixed outlay $\left(\mathrm{C}^{0}\right)$ at fixed input prices.

Let the production function is of the form

$$
y=A x_{1}^{a} x_{2}^{\beta}
$$

and the iso-cost line is

$\mathrm{C}=\mathrm{P}_{1} \mathrm{x}_{1}+\mathrm{P}_{2} \mathrm{x}_{2}+\mathrm{b}$ (general form)

Then

$$
\frac{\partial y}{\partial x_{1}}=\frac{\alpha A}{x_{1}}, \frac{\partial y}{\partial x_{2}}=\frac{\beta A}{x_{2}}
$$

and the equilibrium condition is

$$
\frac{\frac{\partial y}{\partial x_{1}}}{\frac{\partial y}{\partial x_{2}}}=\frac{\alpha x_{2}}{\beta x_{1}}=\frac{P_{1}}{P_{2}}
$$

i.e. $\alpha x_{2} P_{2}-\beta x_{1} P_{1}=0$

This is called the expansion path

From the iso-cost equation

$$
\mathbf{P}_{1} \mathbf{x}_{1}=\mathrm{C}-\mathbf{P}_{2} \mathbf{x}_{2}-\mathrm{b}
$$

Substituting in the expansion path

$$
\begin{gathered}
\alpha x_{2} P_{2}-\beta\left(C-P_{2} x_{2}-b\right)=0 \\
\therefore x_{2}=\frac{\beta}{\alpha+\beta}\left(\frac{C-b}{P_{2}}\right) \\
x_{1}=\frac{\alpha}{\alpha+\beta}\left(\frac{C-b}{P_{1}}\right)
\end{gathered}
$$

$\therefore y=A\left[\frac{\alpha}{\alpha+\beta}\left(\frac{C-b}{P_{1}}\right)\right]^{\alpha}\left[\frac{\beta}{\alpha+\beta}\left(\frac{C-b}{P_{2}}\right)\right]^{\beta}$

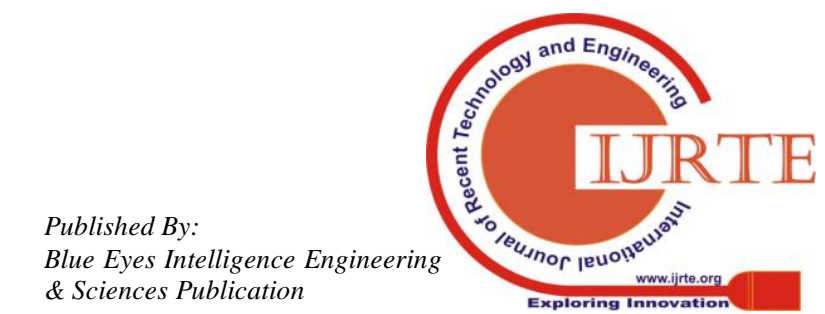




$$
\begin{aligned}
\therefore y= & A\left[\frac{\alpha}{\alpha+\beta}\left(\frac{c-b}{P_{1}}\right)\right]^{\alpha}\left[\frac{\beta}{\alpha+\beta}\left(\frac{c-b}{P_{2}}\right)\right]^{\beta} \\
\therefore y^{\frac{1}{\alpha+\beta}} & =\left[\frac{A \alpha^{\alpha} \beta^{\beta}}{P_{1}^{\alpha} P_{2}^{\beta}}\right]^{\frac{1}{\alpha+\beta}} \cdot \frac{c-b}{\alpha+\beta}
\end{aligned}
$$$$
\therefore C=(\alpha+\beta)\left(A \alpha^{\alpha} \beta^{\beta}\right)^{-\frac{1}{\alpha+\beta}} y^{\frac{1}{\alpha+\beta}} P_{1} \frac{\alpha}{\alpha+\beta} P_{2} \frac{\beta}{\alpha+\beta}+b
$$

$\alpha+\beta \quad$ is called the returns to scale, be denoted by $R$. Then

$$
C=R\left[A \alpha^{\alpha} \beta^{\beta}\right]^{-\frac{1}{R}} \frac{1}{R_{P}}{ }_{1}^{\frac{\alpha}{R}} P_{2} \stackrel{\beta}{R}+b
$$

i.e., $\mathrm{C}$ is of the form

$$
C=K y^{\frac{1}{R}} P_{1}^{\frac{\alpha}{R}} P_{2} \frac{\beta}{R}+b
$$

Where

$$
K=R\left[A \alpha^{\alpha} \beta^{\beta}\right]^{-\frac{1}{R}}
$$

In the case of $\mathrm{n}$ inputs, it takes the form

$$
C=K y \stackrel{\frac{1}{R}}{P_{1}} \frac{a_{1}}{R} P_{2} \frac{a_{2}}{R} \ldots . . P_{n} \frac{a_{n}}{R}+b
$$

where

$$
K=R\left[A \alpha_{1} \alpha_{1 \alpha_{2}} \alpha_{2} \ldots \ldots \alpha_{n} \alpha_{n}\right]^{\frac{-1}{R}}
$$

This cost structure is the basic for the assumption of AIDS

To derive the AIDS model, let the logarithm of the cost function for a given utility level $\mathrm{U}$ and price $\mathrm{P}$ be of the form

$\log C(U, P)=a_{0}+\sum_{k} a_{k} \log P_{k}+\frac{1}{2} \sum_{k} \sum_{j} g_{k j} \log P_{k} \log P_{j}+U B_{0} \Pi P_{k} B_{k}$

$$
\text { By definition } \frac{\partial C}{\partial P_{i}}=q_{i}(U, P)=q_{i}(\text { say })
$$

Where $\mathrm{C}=\mathrm{C}(\mathrm{U}, \mathrm{P})$

$$
\begin{aligned}
& \therefore \frac{\mathrm{P}_{\mathrm{i}}}{\mathrm{C}} \cdot \frac{\partial \mathrm{C}}{\partial \mathrm{P}_{\mathrm{i}}}=\frac{\mathrm{P}_{\mathrm{i}} \mathrm{q}_{\mathrm{i}}}{\mathrm{C}} \\
& \quad \text { i.e., } \frac{\partial \log \mathrm{C}}{\partial \log \mathrm{P}_{\mathrm{i}}}=\frac{\mathrm{P}_{\mathrm{i}} \mathrm{q}_{\mathrm{i}}}{\mathrm{C}}=\mathrm{w}_{\mathrm{i}} \text { (say) }
\end{aligned}
$$

$\mathbf{w}_{\mathbf{i}} \quad$ is the expenditure share of the $\mathbf{i}^{\text {th }}$ good

From (16)

$$
\frac{\partial \log C}{\partial \log P_{i}}=a_{i}+\sum_{j} g_{i j} \log P_{j}+U B_{0} B_{i}, \prod_{k} P_{k}{ }^{B}
$$

$$
\text { i.e.. } w_{i}=a_{i}+\sum_{j} g_{i j} \log P_{j}+U B_{0} B_{i} \prod_{k} P_{k}^{B_{k}}
$$

Denote C(U.P) in (16) by Y. Then

$$
\begin{aligned}
& \log Y=a_{0}+\sum a_{k} \log P_{k}+\frac{1}{2} \sum_{k} \sum_{j} g_{k j} \log P_{k} \log P_{j}+U B_{0} \prod_{k} P_{k} B_{k} \\
& \therefore U B_{0} \prod_{k} P_{k} B_{k}=\log Y-\left[a_{0}+\sum_{k} a_{k} \log P_{k}+\frac{1}{2} \sum_{k} \sum_{j} g_{k j} \log P_{k} \log P_{j}\right]
\end{aligned}
$$

Substituting this in (17)

$w_{i}=a_{i}+\sum_{j} g_{i j} \log P_{j}+B_{i}\left[\log Y-\left(a_{0}+\sum a_{k} \log P_{k}+\frac{1}{2} \sum_{k} \sum_{j} g_{k j} \log P_{k} \log P_{j}\right)\right]$

Then the AIDS in the budget share form is

$$
w_{i}=a_{i}+\sum_{j} g_{i j} \log P_{j}+B_{i} \log \left(\frac{Y}{P}\right), \quad i=1,2, \ldots . n
$$

Where $\mathrm{P}$ is the price index defined in terms of individual prices given by

$$
\log P=a_{0}+\sum_{k} a_{k} \log P_{k}+\frac{1}{2} \sum_{k} \sum_{j} g_{k j} \log P_{k} \log P_{j}
$$

The summation restrictions imply

$$
\sum_{\mathrm{i}} \mathrm{a}_{\mathrm{i}}=1, \quad \sum_{\mathrm{j}} \mathrm{g}_{\mathrm{ij}}=0 . \sum_{\mathrm{i}} \mathrm{B}_{\mathrm{i}}=0 \text { : Additive condition }
$$

$$
\sum_{\mathrm{j}} g_{\mathrm{ij}}=0 \text { :Homogenity conditon }
$$

\section{$\mathrm{g}_{\mathrm{ij}}=\mathrm{g}_{\mathrm{ji}}:$ Symmetry condition}

These conditions will ensure that the system satisfies the additivity, homogeneity in prices and income and the Slutsky symmetry conditions.

Here

$a_{i}, B_{i}, g_{i j} ; i, j=1,2 \ldots \ldots n$ are parameters.

The non-linearity of these sets of equations requires the use of maximum likelihood methods of estimation.

For estimation purpose $\mathrm{P}$ is approximated to the price index given by $\log P=\sum_{k} w_{k} P_{k}$

Where $\mathrm{w}_{\mathrm{k}}$ is the weight of $\mathrm{P}_{\mathrm{k}}$

In addition to the above, if the household size also is to be taken in the function, it is modified as

$$
w_{i}=a_{i}+\sum_{j} g_{i j} \log p_{j}+B_{1} \log \left(\frac{Y}{P}\right)+\theta_{i} \log S, \quad i=1,2 \ldots \ldots . n
$$

where

$\mathbf{w}_{\mathbf{i}}=$ average budget share of the $\mathrm{i}^{\text {th }}$ commodity

$\mathrm{p}_{\mathrm{j}}=$ the price of the $\mathrm{j}^{\text {th }}$ commodity

$\mathrm{Y}=$ per capita food expenditure

$\mathrm{S}=$ household size

and $\log \mathrm{P}=\sum \mathrm{w}_{\mathrm{k}} \log \mathrm{P}_{\mathrm{k}}$ is the geometrically weighted price index used to deflate the income variable.

The demand elasticities corresponding to the above AIDS are: 
(i)

Own price elasticity $e_{i i}=\frac{g_{i i}-B_{i} w_{i}}{w_{i}}$

$$
\begin{aligned}
& \text { Cross price elasticity } \\
& \qquad e_{i j}=\frac{g_{i j}-B_{i} w_{j}}{w_{i}} \\
& \text { Real expenditure elasticity }
\end{aligned}
$$

$$
e_{i y}=\frac{B_{i}}{w_{i}}+\frac{g_{i i}-B_{i} w_{i}}{w_{i}}
$$

Household size elasticity

$$
e_{\text {is }}=\frac{\theta_{i}-B_{i}}{w_{i}}
$$

\section{RESULTS OF FUNCTIONAL ANALYSIS}

\section{Expenditure System- Econometric Results}

The structural parameter estimates are of interest largely for technical comparisons, as number of estimated parameters of AIDS is statistically significant. The statistical significance of these Coefficients suggest that demand of food and non food items are responsible for prices, the total expenditure level and house hold size (Tesfaye Telku et. Al (1988).

\section{Food items}

Here we attempt to produce a complete set of food demand parameters on an experimental basis. Two demand systems such as the Almost Ideal Demand System (AIDS) and multinomial Linear Logit model (MLLM) are estimated using a single cross section survey. The estimates are used to highlight food demand structure in the four different socio-economic regions, to show their utility for policy analysis and to evaluate the empirical performance of the two demand systems. In addition, the estimates are positioned relative to other studies in selected Asian countries

Linear version of the AIDS and MLLM are used to estimate the food demand systems for the four groups viz. A group of 72 house holds in Midalam.

The AIDS model allows an evaluation of the compatibility of the estimated system with the restrictions from the individual consumer demand theory. It is among the most flexible of the currently available demand system models, permitting a wide range of tests of consumer preferences. The MLLM satisfies non-negativity and Engel aggregation properties of consumer demand theory. In addition homogeneity and symmetry restrictions can be imposed by applying linear restrictions on the system parameter. Parameter estimates based on these two demand models for all the four groups are presented to provide users with alternative sets of information and a basis on which to compare their empirical performance. Information from the survey sections on household food expenditure and demographic characteristics was utilized for the estimation of the two demand system. Seven food commodity groups viz: (i) Rice, (ii) Pulses and other Cereals (iii) Spices and condiments (iv) Fish (v) Meat and meat products (vi) Vegetables (vii). Fruits (viii) Milk and Milk products. (ix) Oil and (x). Sugar and jaggers all other consumable items were used taking into consideration the traditional consumption pattern and government policy priorities. Household expenditure on each group was the money value of the food purchased used from inventory or received as transfers during the survey period.

Total food expenditure, the sum of expenditures on all these food groups, was used as a measure of income variable in the food demand system. Household expenditure on each food group as a fraction of total food expenditure was calculated as household-specific food budget shares.

No market prices were available on the survey data. Price indexes for these ten food groups were computed at the district level. District level implicit prices were constructed for individual commodities in each food group. The prices in each group were then geometrically weighted using district level mean value shares. Implicitly households in a district were assumed to face similar district level price indexes.

Household size, the only demographic variable, was simply defined as the number of persons in a household.

The additive error term $\left(e_{t}\right)$ for each equation in both systems were assumed to be $e_{t} \sim \mathrm{N}\left(0, \sigma^{2} \mathrm{I}\right)$. A Contemporaneous Covariance $\mathrm{V}(\mathrm{e})=\Sigma \theta \tau$ was used recognizing that the specifications are in fact approximations and that food expenditure at each household level are interrelated.

The models were estimated with adding up homogeneity and symmetry restrictions imposed. In the case of MLLM these restrictions were imposed locally at sample mean budget shares. In order to get efficient estimators, parameter estimates from the more aggregate commodity level were used to restrict the estimates at the disaggregate level. To ensure that the covariance matrix was non-singular ten budget equations were estimated.

The miscellaneous food group was deleted in the AIDS estimation, but the same was used to normalize food budget shares in MLLM.

An interactive seemingly unrelated regression was applied to estimate the structural parameters.

The MLLM parameters measure the relative budget share responses to changes in food prices, total food expenditure and household size.

But from the form of the equation, it is evident that the individual structural parameters for the MLLM cannot be used directly to evaluate and interpret responses to the conditioning variables on food demands. In order to compare the results of the two demands system, they are converted to estimated elasticities.

\section{Midalam}

Estimated parameters based on AIDS for major food groups in the selected regions are presented in Table 1. 
Table 1: Parameter estimates based on Almost Ideal Demand System for major Food groups in the Midalam Households

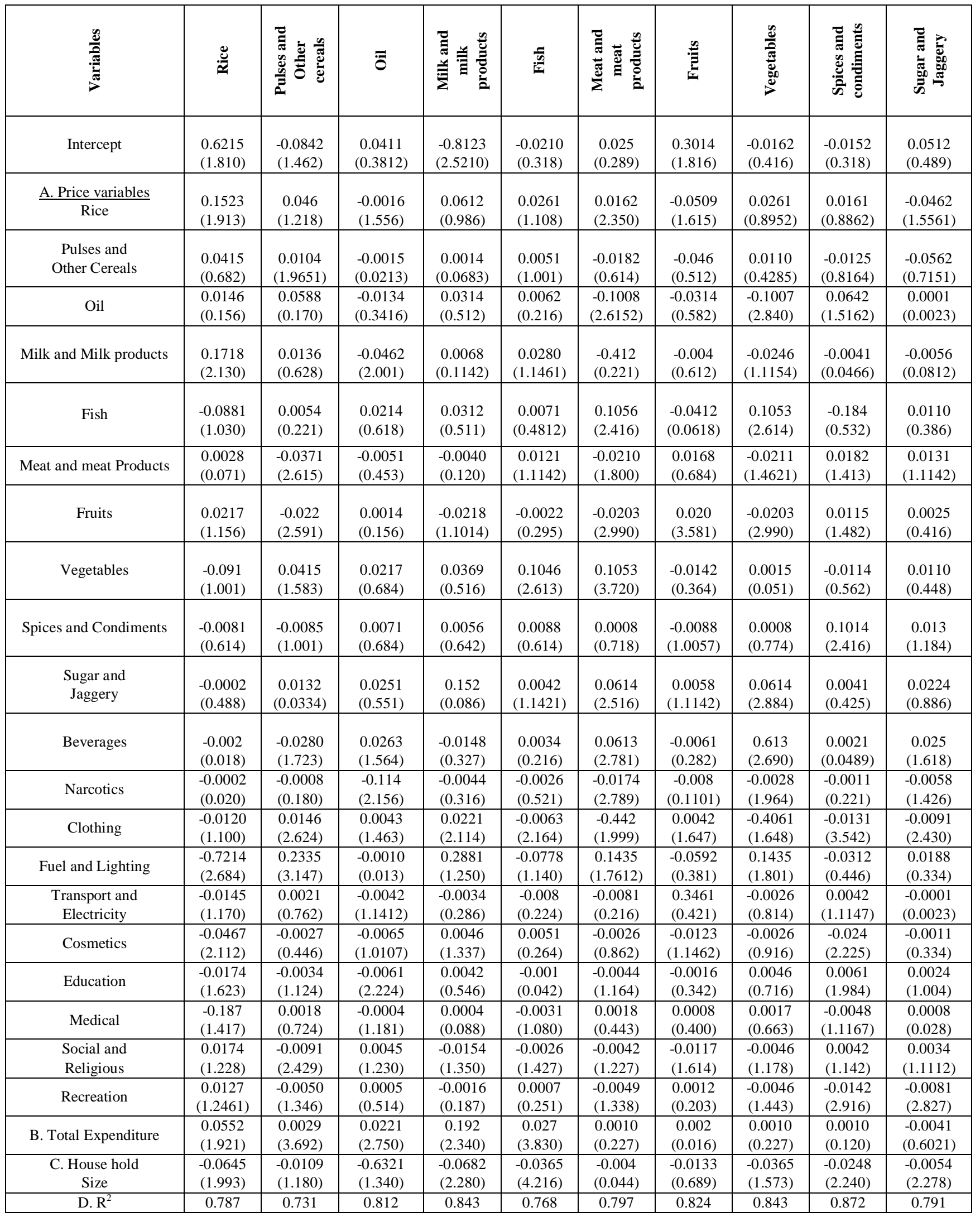

The expenditure Coefficient is significant for the commodities pulses and other cereals, fish, oil, milk and milk products and rice for the Midalam village panchayat households. This shows that the expenditure share on pulses and other cereals, Fish, oil, milk and milk products and rice will increase with an increase in real income (total expenditure) with prices held constant. The expenditure coefficients for all the commodities are positive except for sugar and jaggery. The nature of the demand for food and non-food commodities could be directly inferred from the signs of the AIDS parameters. 
Commodities with negative expenditure parameters are income inelastic and those with positive parameters areincome inelastic and all other commodities are elastic. The household size coefficient is negative for all the commodities and significant for the commodities rice, milk and milk products, fish, spices and condiments and sugar and jaggery. Thus the expenditure share on these items would decrease with the increase in the household size, reflecting economics of scale and the larger household may get unit price reductions as they purchase lumpsum quantities.

The price coefficient of meat and meat products alone is negative and significant in the rice equation for this group. Thus the increase in prices of this commodity will decrease the expenditure share on rice. Similar arguments hold for the significant Coefficients in the other commodity share equations. For example the expenditure share equation for fish shows that the expenditure on meat and meat products reduces the expenditure share on fish.

\section{REFERENCES}

1. Abdulai, A.,D.Jain and A.Sharma. 1999. "Household Food Demand Analysis in India." Journal of Agricultural Economics. 50: 316-327.

2. AbulWadud(2006) in his study on the meat demand in Bangaladesh using the Almost Ideal Demand System, The Empirical Economics Letters,5(1): (January 2006)

3. Barten,A.P., and C. Vanloot,1996. "Price Dynamics in Agriculture: An Exercise in Historical Econometrics." Economic Modelling. 13: 315-331.

4. Becker, G.S. 1965. "A Theory of Allocation of Time." Economics Journal. 75: 493-517.

5. Bhalla, G.S., P.Hazell and J.Kerr. 1999. "Prospect's for India's Cereal Supply And Demand 2020." Food, Agriculture, and the Environment, Discussion Paper 29, International Food Policy and Research Institute.

6. Brahmananda,P. 1997. "50 years of Free Indian Economy," Indian Economic Association Trust for Research and Development, New Delhi, India.

7. Carpio,C. 2000, "Production Response of Cotton in India, Pakistan and Australia."M.S Thesis, Texas Tech University, Lubbock, Texas

8. Chalfant, J.A. (1987). 1987, "A Globally Flexible, Almost Ideal Demand System.” Journal of Business and Economic Statistics. 5:233-242.

9. Chavas, J. and M.Holt. 1990. "Acreage Decision Under Risk: The Case of Corn and Soybeans." American Journal of Agricultural Economics. 72(3): 529-538.

10. "CIA - The World Factbook 2002 - India." Available on-line. http://www.odci.gov/cia/publications/factbook 